\title{
An algorithm for comparative analysis of power and storage systems for maritime applications
}

\author{
Massimo Rivarolo $^{l}$, Federico Iester ${ }^{l}$, Aristide F. Massardo ${ }^{l}$ \\ ${ }^{1}$ Thermochemical Power Group (TPG), DIME, University of Genoa, Via Montallegro 1, 16145 Genoa, Italy
}

\begin{abstract}
This paper presents an innovative algorithm to compare traditional and innovative energy systems onboard for maritime applications. The solutions are compared adopting a multi-criteria method, considering four parameters (weight, volume, cost, emissions) and their relevance according to the kind of ship and navigation route. The algorithm, which includes a large and updated database of market solutions, leads to the implementation of HELM (Helper for Energy Layouts in Maritime applications) tool. HELM was conceived to support the design of maritime systems: it chooses the best technology comparing traditional marine diesel engines, propulsion systems with alternative fuels (methanol, ammonia, LNG) and innovative low-emission technologies (fuel cell and batteries). Two case studies are investigated: (i) a small passenger ship for short routes (ii) and a large size ro-ro cargo ship. For case (i), fuel cells represent a competitive solution, in particular considering navigation in emission control areas. For case study (ii) Internal Combustion Engines shows are the best solution. The evaluation of alternative fuels is performed, considering a sensitivity analysis on emissions' importance: methanol, LNG, and ammonia are promising solutions. For case (i), the installation of electrical batteries is also evaluated to analyse potential advantages to reduce the amount of $\mathrm{H}_{2}$ stored onboard.
\end{abstract}

\section{Introduction}

As the emission of Green House Gases (GHG) are increasing more and more in last years, reaching the record values of 33.5 Gtons in 2018 and 33.4 Gtons in 2019 in terms of $\mathrm{CO}_{2}$ [1], both international associations and governments are adopting environmental and energy strategies to reduce their growth. According to the last data, the impact of maritime sector is growing as well, with an increase of GHG emissions from 977 million tonnes in 2012 up to nearly 1.1 Gtons in $2018(+9.6 \%)$ [3]. Today almost the total (99.5\%) of maritime vessels in operation employ Internal Combustion Engines (ICEs) for propulsion fed by high pollutant fuel oils (Heavy Fuel Oil, HFO, or Marine Diesel Oil, MDO) [3]. In the last twenty years, the International Maritime Organization (IMO) set many regulations to limit the impact of maritime sector. The document MARPOL Annex VI established limitations SOx and NOx emissions. Since 2020, SOx maximum content in terms of weight in the fuel has been set to $0.5 \%$ (previous limit was $3.5 \%$ ), with a further limitation of $0.1 \%$ in Emission Control Areas (ECA). Concerning NOx emissions, new ships (construction since 2016) must comply with the TIER 3 limit in ECA, which implies a reduction from $14 \mathrm{~g} / \mathrm{kWh}$ to $4 \mathrm{~g} / \mathrm{kWh}$ for navigation at low rated engine speeds ( $<150 \mathrm{rpm})$. In 2018, IMO has also established long-term targets to reduce $50 \%$ GHG emissions in shipping sector by 2050 , compared to 2008 levels.
Recent studies demonstrated that the introduction of alternative fuels and the diffusion of new technologies is mandatory to reach the long-term targets set by IMO. Although the introduction of LNG to replace HFO in ICEs will help to reduce $\mathrm{CO}_{2}$ emissions [5][6], it is not sufficient: thus, the use of more sustainable solutions must be considered as well. The potential of many possible fuels, such as ammonia and methanol, has been investigated in [7][8][9]. In recent years, the introduction of fuel cells as energy generation systems for propulsion or auxiliary power units (APU) for maritime vessels has been investigated by many authors, in particular PEMFC and SOFC technologies appear to be the most promising ones $[10][11][12][13][14][15][16]$. Fuel cells present many interesting features for maritime applications, such as high efficiency (also at partial loads), low level of emissions, noise and vibrations. However, it should be noted that this technology is currently available only for limited power range, up to 1-2 MW, thus they cannot substitute traditional ICE for propulsion on large size ships (i.e. containerships, tankers, large cruise ships).

As many solutions for both energy generation and storage onboard are available on the market and new innovative solutions are under analysis, it is important to adopt instruments and software tools to compare them with state-of-the-art solutions and find out the most promising ones, also according to the operating scenario and the vessel navigation route. For maritime applications, a holistic evaluation is mandatory to consider many relevant parameters, such as costs,

\footnotetext{
* Corresponding author: massimo.rivarolo@unige.it
} 
emissions, volumes and weights. In this research paper a simple but reliable method for a preliminary evaluation of the solutions currently available on the market is presented: the developed approach allows for calculating the values of these parameters for different technologies, based on a strong database implemented inside the software tool and based on real market data for each storage and energy generation technology. The algorithm is based on a multi-criteria decision method, which is employed to compare many solutions, also in maritime applications [17][18][19].

\section{Algorithm description}

The HELM algorithm is based on a wide specifics database of different power systems and their corresponding fuel storage. Once obtained the data from the literature the software creates a set of maps with information that covers a large range of sizes. The main inputs are the power required by the ship and the hours of operation. In the latest version of the software, there is one more feature required as input that leads to the possibility of introducing the use of the battery, covering variable percentages, as a second technology in the same study case to help innovative ones like fuel cells.

Figure 1. shows the flow chart that describes the algorithm on which the software depends that was already explained in previous works by the authors' research group [20][21][22]. It starts from the main inputs, then entering the maps, evaluates the weight, volume, and cost of the system including both the energy consumption unit and the fuel supply and storage systems. Furthermore, there are maps used to estimate the emissions as a function of the fuel and the type of generating system.

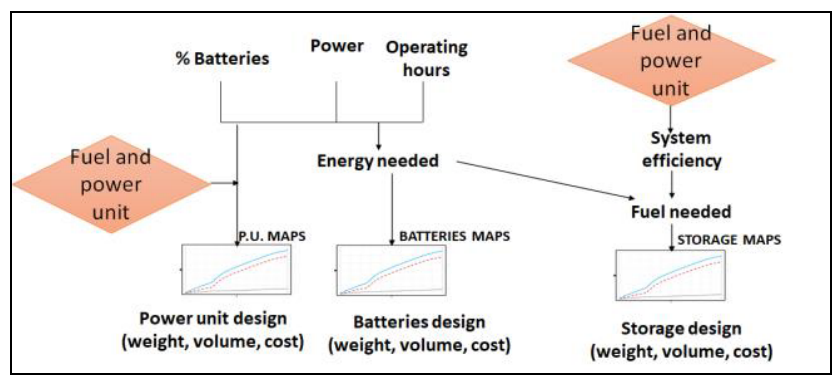

Fig. 1. Algorithm flow chart

The second part of the software code establishes a comparison between the different technologies considered in the first part. To implement this phase, four areas of comparison are considered, which are the same outputs described above (weight, volume, cost, and emissions), then the software gives scores according to the performance of each technology for all the four fields and after rates are added.

Table 1. describes the criteria by which the scores are awarded. The scores range from 1 up to 10 for each class, the technology with the best performing value takes 10 , used a reference value (Vbest) to evaluate the scores of the other technologies (Vi) using the following formula:

$$
X_{i}=V_{i} / V_{\text {best }}
$$

To expand the case study and to adapt the computation to different situations, the software uses references that are nothing more than weights, which give different importance to the various parameters (weight, volume, cost, and emissions). The reference value ranges from 1 to 5 and multiplies the corresponding score. In this way, new low RTL technologies with performances that are not as excellent as those of traditional systems but with low polluting emissions can withstand and in some cases win the comparison.

Table 1. Scores in function of the $X$ range of a certain output variable.

\begin{tabular}{|cccc|}
\hline Value & Score & Value & Score \\
$1<\mathrm{X} \leq 1.1$ & 10 & $3<\mathrm{X} \leq 4$ & 5 \\
$1.1<\mathrm{X} \leq 1.3$ & 9 & $4<\mathrm{X} \leq 5$ & 4 \\
$1.3<\mathrm{X} \leq 1.6$ & 8 & $5<\mathrm{X} \leq 6$ & 3 \\
$1.6<\mathrm{X} \leq 2$ & 7 & $6<\mathrm{X} \leq 8$ & 2 \\
$2<\mathrm{X} \leq 3$ & 6 & $\mathrm{X}>8$ & 1 \\
\hline
\end{tabular}

One of the greatest advantages of HELM, besides its ease of use, is that its database can be constantly updated to provide reliable data and solutions able to consider even the most recent technologies in the maritime sector, with also the possibility of analysing hybrid solutions (i.e., combining batteries and fuel cells). It is possible to include a new technology simply by inserting the maps in the program code. The functions are periodically updated based on the most recent market values: the detailed maps for each energy generation and storage technology concerning volume, weights, costs, and emissions are reported in [21]. At present, HELM database is made by hundreds of commercial solutions: for innovative technologies (i.e. SOFC), only a few market solutions exist, while for traditional ones (i.e. ICE fed by MDO) nearly 100 market values are included in the database. The possible different solutions are reported in Table 2 .

Table 2. Technologies implemented in HELM database

\begin{tabular}{|l|l|}
\hline Power generation system & Storage system \\
\hline PEM Fuel Cells (PEMFC) & Liquid H2 (LH2) \\
\hline PEM Fuel Cells (PEMFC) & Compressed H2 (CH2) \\
\hline $\begin{array}{l}\text { Solide Oxyde Fuel Cells } \\
\text { SOFC) }\end{array}$ & Liquid Natural Gas (LNG) \\
\hline microGT (mGT) & Liquid Natural Gas (LNG) \\
\hline Int. Comb. Engine (ICE) & methanol \\
\hline Int. Comb. Engine (ICE) & ammonia \\
\hline Int. Comb. Engine (ICE) & Liquid Natural Gas (LNG) \\
\hline Int. Comb. Engine (ICE) & Marine Diesel Oil (MDO) \\
\hline
\end{tabular}


To facilitate the use of the software and speed up data collection, additional functions have been implemented to calculate all the possible input ranges and then to represent the results, indeed some graphical representations are reported in the following chapters.

\section{Case studies}

Two case studies have been chosen for presentation in this paper, based on their size and on the characteristics of their operative usage.

\subsection{Small size case study: passenger ship for fluvial transport, Jules Verne 2}

This case study is a small sized ship for public fluvial transport in Nantes, France. This bus-ship has been in operation since August 2019, and it is one of the first passenger ships in the world fully powered by hydrogen. It operates throughout the whole year to connect PortBoyer and Petit Port on the river Erdre, at one kilometre, and it is powered by PEM fuel cells (installed power 10 $\mathrm{kW}$ ) that enable the ship to transport up to twelve passengers and eight bikes.

Observing the ship's most recent navigation activity [23], the operating hours are assumed equal to 24. Since ships rarely need to exploit their power units to the maximum of their capabilities, a load profile has been investigated based on the methodology described in [24], and later processed via a weighted average of the energy loads during the navigation, yielding a corrective energy factor, expressed in percentage, and applied to the operative hours of the case study. Fig. 2 shows the load profile for two passenger ship types, coastal and oceangoing vessels, through which the equivalent hours turned out to be equal to $19 \%$ and $28 \%$ of the whole navigation time respectively. In this case, the weighted average considered is the first one, bringing the 24 hours mentioned above to 5 equivalent hours.

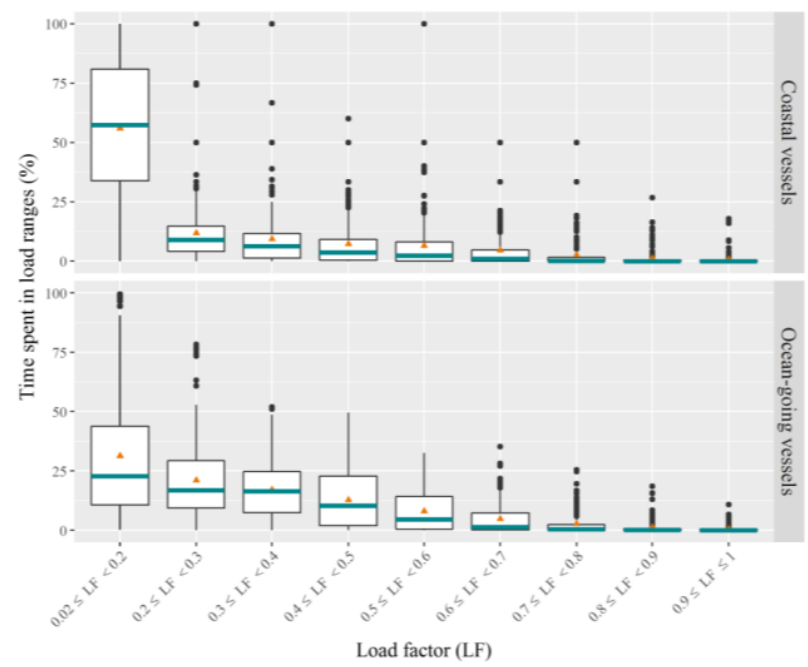

Fig. 2. Load factor for two passenger ships classes [24].

After defining power $(10 \mathrm{~kW})$ and equivalent hours (5), the relevance of the four parameters used in HELM has to be set. As this ship needs to operate always in urban areas, a high relevance must be considered for emissions, which has been set to 5 . Volumes must have a high relevance as well because space is a critical factor for passenger transportation, and the same can be said, to a lesser extent, for the weight, resulting in volume having a relevance of 3 , and weight being assigned 2 . Costs are less relevant than the other parameters for such a small sized ship, thus relevance is set to 1 , also thanks to incentives.

\subsubsection{Simulation results}

In this case study's results (Fig. 3), PEMFC showed great potential due to the nature of the ship, requiring low power and only few equivalent operating hours. Among the other technologies, the fuel oil ICE obtains a high score thanks to its maturity, which leads to low volume, weight and cost, while emissions are its weakness. It is worth analysing the absolute values for the best potential choices (PEMFC fed by liquid or compressed hydrogen and ICE fed by fuel oil), comparing the impact of both storage and propulsion systems on the results. As far as volume and weight are concerned, Fig. 4 shows that the largest impact is due to the propulsion unit in case of ICE; on the other hand, the impact of the storage system is considerable in case of PEMFC solutions, due to the large volumes and weight required for $\mathrm{H}_{2}$ storage onboard. Concerning costs, it is evident that the propulsion system represents the largest amount for each technology, because the required autonomy is limited (5 hours) and the related size of storage system does not affect significantly total costs.

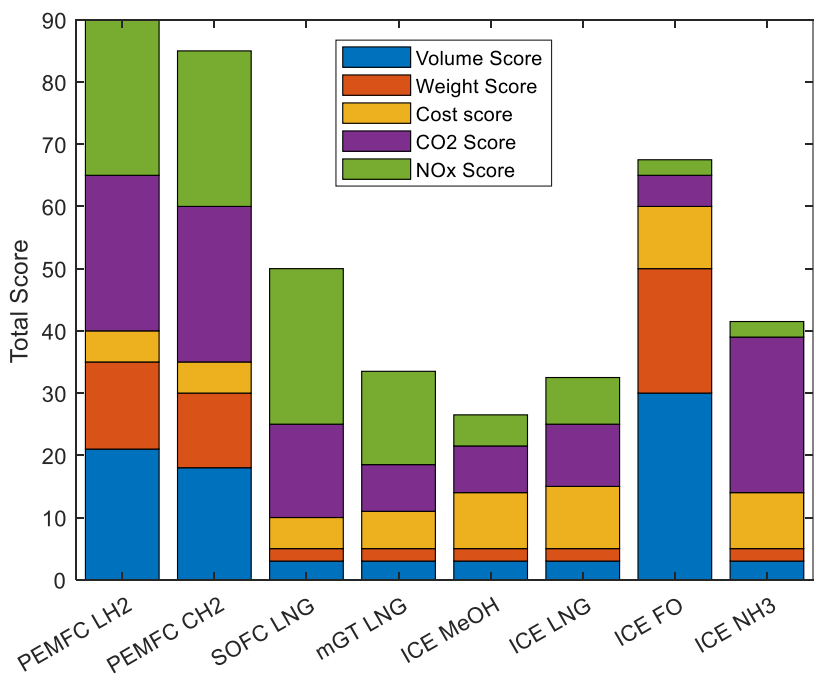

Fig. 3. Comparative HELM results for small case study (Jules Verne 2) 


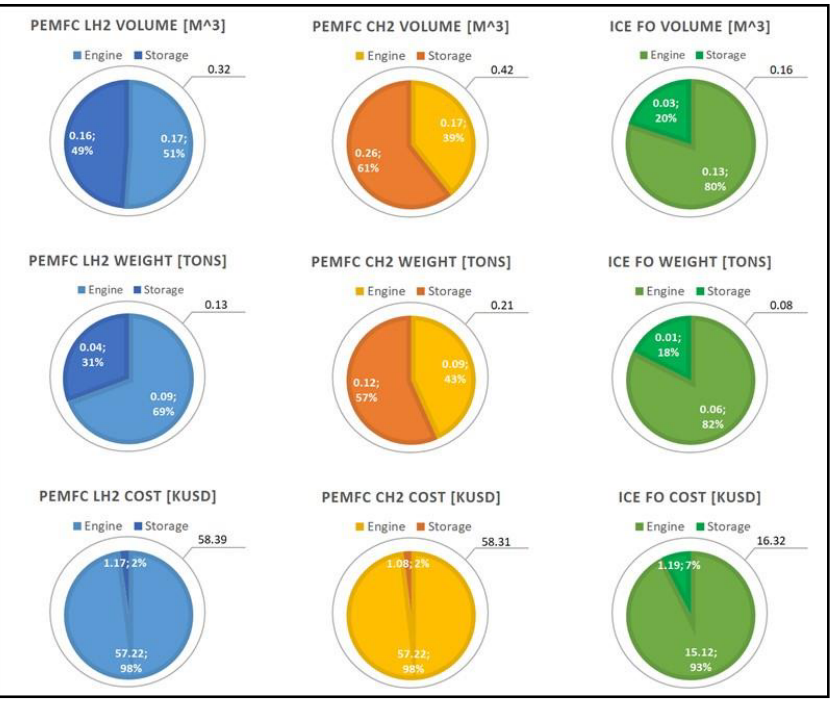

Fig. 4. Propulsion and storage systems comparison for the best technologies (Jules Verne 2)

To further analyse the results' range of validity, a parametric analysis has been conducted (Fig. 5) repeating the simulation while assigning every time a different emissions relevance (1, 3 and 5) and normalising the scores of all technologies of each simulation so that their sum would be the same with the three different relevance sets, in order to make the changes easily noticeable. It is worth noting that the fuel oil ICE is the best choice only in a scenario with very low relevance for emissions; PEMFC fuelled by hydrogen are a competitive solution for this application, as the limited power demand and autonomy required does not require large volumes for hydrogen storage onboard.

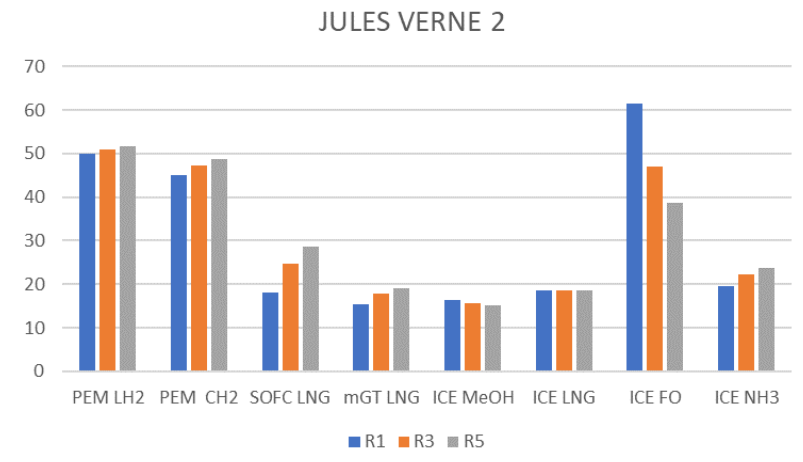

Fig. 5. Parametric analysis of the scores of the small sized case study, with the relevance of the emissions being set to 1,3 and 5 (blue, orange and grey bars).

\subsection{Large size case study: Ro-Ro ship, F. A. Gauthier}

This case study is a large size ship operating in Canadian waters since 2015, connecting Bas-Saint-Laurent to Godbout and Baie-Comeau, and built in 2013 in Italy by Fincantieri. With a length of 130 meters and a width of 25 , it can transport up to 800 passengers and 180 cars. It has been the first LNG-powered ferry used in North America, and the first one of this kind to be built in Italy.
It's propelled by 4 Wärtsilä Dual Fuel LNG/MDO engines, with a total power of $20880 \mathrm{~kW}$.

Searching for the ship's most recent navigation activity, it has been assigned 48 operating hours. Following the same process described for the first case study [23], a load profile has been searched for and processed, obtaining a corrective consumed energy factor of $33 \%$ that correspond to the Ocean-going vessels case shown in Fig. 6. The final equivalent hours amount to roughly 16 .

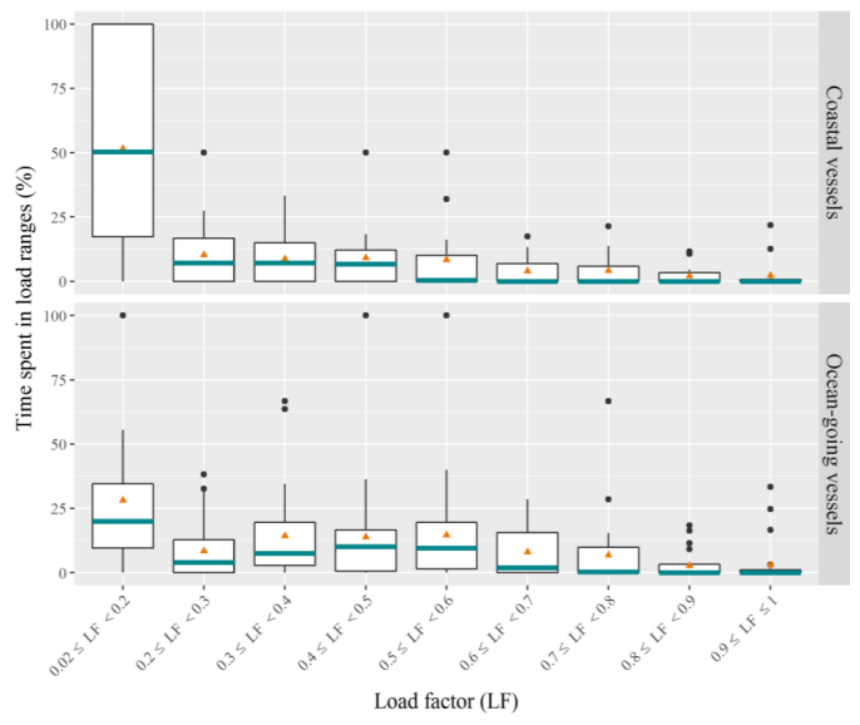

Fig. 6. Load factor for two Ro-Ro ships classes [24].

With power (20880 kW) and equivalent hours (16) defined, the relevance of the four parameters needed to be defined. In this case, as this ship needs to be able to store a large number of vehicles and passengers, volume is critical, thus a relevance of 4 has been assigned. For such a large ship, costs are also an important factor, leading to an assigned relevance of 3 , while weight is less critical than volume, therefore relevance 2 has been assumed. The same value has been imposed for emissions, as navigation does not occur in ECA zones or in locations with specific requirements.

\subsubsection{Simulation results}

In this case study's results (Fig. 7), the combination of medium-high power requirements and few equivalent hours set up the field for a good result for LNG ICEs. The absence of SCR systems makes the typical advantage of FO engines in terms of weight and volume vanishes, as the storage does not need to be particularly large. As the required power is quite high (about $20 \mathrm{MW}$ ), fuel cell solutions are not particularly competitive, confirming that nowadays they are an interesting alternative to traditional ICEs only for small size applications. 


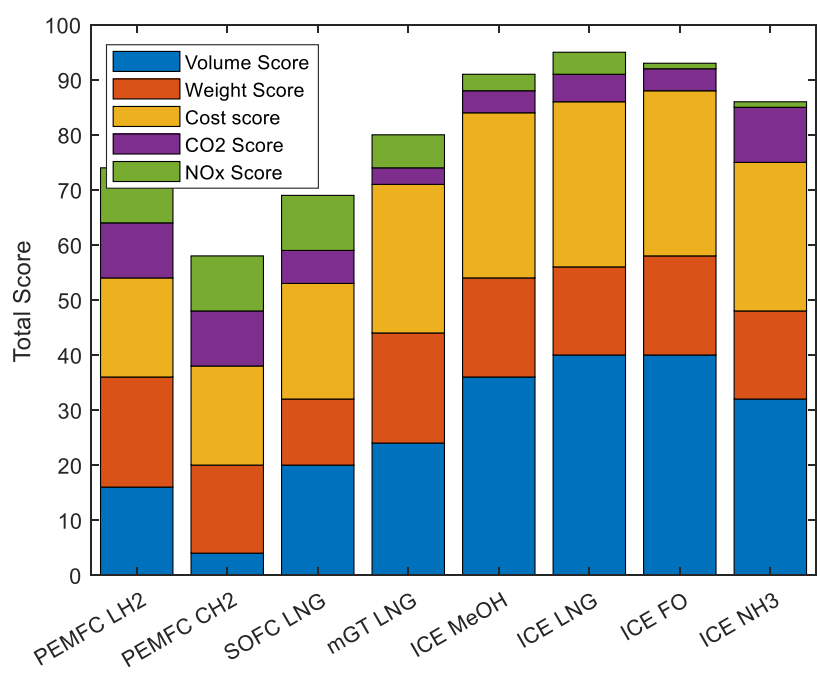

Fig. 7. Comparative HELM results for small case study (Gauthier Ro-Ro ship)

Tab. 3 shows the impact of propulsion and storage systems for the solutions that obtain the highest score (Fig. 7). Fuel oil is slightly superior to $\mathrm{LNG}$ and methanol in terms of volume, weight and costs, but the difference is limited; from the environmental standpoint, LNG and $\mathrm{MeOH}$ arouse interest, thus they can both represent an interesting alternative for the present scenario as well.

Tab. 3. Propulsion and storage systems comparison for the best technologies (Gauthier Ro-Ro ship)

\begin{tabular}{|c|l|r|r|r|}
\cline { 2 - 5 } \multicolumn{1}{c|}{} & \multicolumn{1}{l|}{\begin{tabular}{l} 
ICE \\
\multicolumn{1}{c|}{ LNG }
\end{tabular}} & \multicolumn{1}{c|}{ ICE FO } & \multicolumn{1}{l|}{ MeOH } \\
\hline Volume & Engine & 578.65 & 686.95 & 643.10 \\
[m^3] & Storage & 274.27 & 101.60 & 277.63 \\
& Total & $\mathbf{8 5 2 . 9 2}$ & $\mathbf{7 8 8 . 5 5}$ & $\mathbf{9 2 0 . 7 3}$ \\
\hline \multirow{2}{*}{ Weight } & Engine & 600.44 & 555.41 & 553.32 \\
[tons] & Storage & 31.38 & 10.26 & 14.76 \\
& Total & $\mathbf{6 3 1 . 8 2}$ & $\mathbf{5 6 5 . 6 7}$ & $\mathbf{5 6 8 . 0 8}$ \\
\hline \multirow{2}{*}{ Cost } & Engine & 12058.16 & 11483.96 & 11943.32 \\
[kUSD] & Storage & 238.33 & 50.45 & 21.16 \\
& Total & $\mathbf{1 2 2 9 6 . 4 8}$ & $\mathbf{1 1 5 3 4 . 4 1}$ & $\mathbf{1 1 9 6 4 . 4 7}$ \\
\hline
\end{tabular}

It is interesting to note that, by looking at the parametric analysis data presented (Fig. 8), LNG ICEs show the same score as FO ICEs in the case of emissions having minimum relevance $(\mathrm{R} 1)$. This shows that LNG is now a viable and convenient solution for ships operating in similar conditions as those presented in this case study, not needing a strong importance in emissions restrictions to be competitive.

\section{F. A. GAUTHIER}

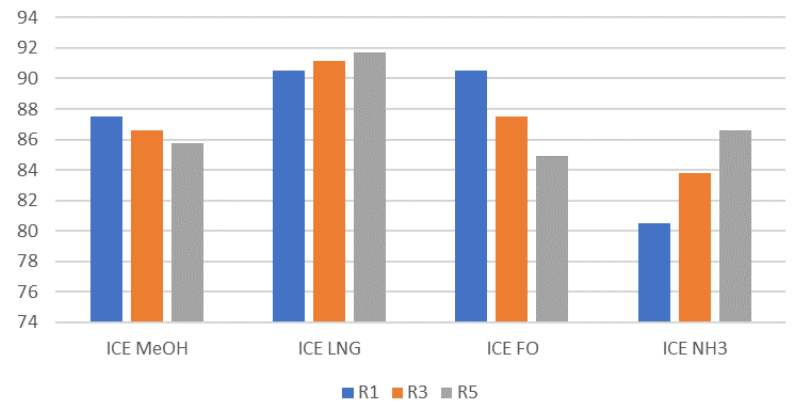

Fig. 8. Parametric analysis of the scores of the large sized case study, with the relevance of the emissions being set to 1, 3 and 5 (blue, orange and grey bars).

\subsection{Batteries analysis}

In order to investigate the level of maturity of Li-Ion batteries for maritime application, an analysis in two steps has been performed. Initially, batteries have been applied to the case study described in section 3.1 (Jules Verne 2); then, a large parametric dataset has been produced to investigate the conditions in which the batteries excel or show their drawbacks.

\subsubsection{Batteries applied to a small sized case study}

The Jules Verne 2 ship represents a good case study to investigate the effect of the adoption of batteries on small ships with low power and operating hours requirements. With the parametric analysis performed (Fig. 9), it becomes apparent how adopting batteries does not increase the overall performance, because of the weight being considerably higher (batteries are characterised by low gravimetric energy density [25]) and the volume being slightly higher as well, due to the low convenience of using both fuel cells (with hydrogen storage) and batteries in parallel considering such a low energy storage requirement. The main advantage in using batteries is due to the possibility of having an additional option during operations, increasing flexibility. On the other hand, they represent an extra cost, volume and weight onboard.

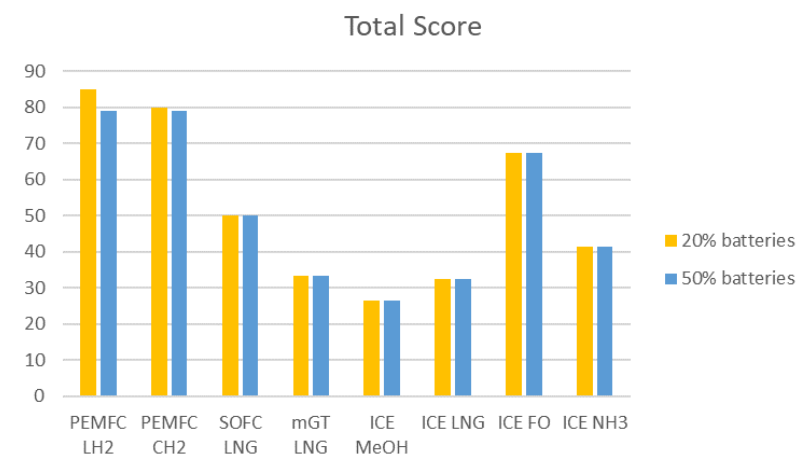

Fig. 9. Results of the small sized case study when imposed $20 \%$ and $50 \%$ batteries usage over the total of consumed energy. 


\subsubsection{Parametric dataset analysis}

From the parametric analysis (Fig. 10), it is evident that batteries show better performance for low powers and high operating hours values. When the operating hours increase, the volume of the storage of hydrogen grows so much that batteries, even if much heavier, show better results. On the other hand, for low operating hours, fuel cells show significantly better scores, thanks to their lower weight. Concerning costs, batteries have lower costs compared to PEMFC and hydrogen storage systems.
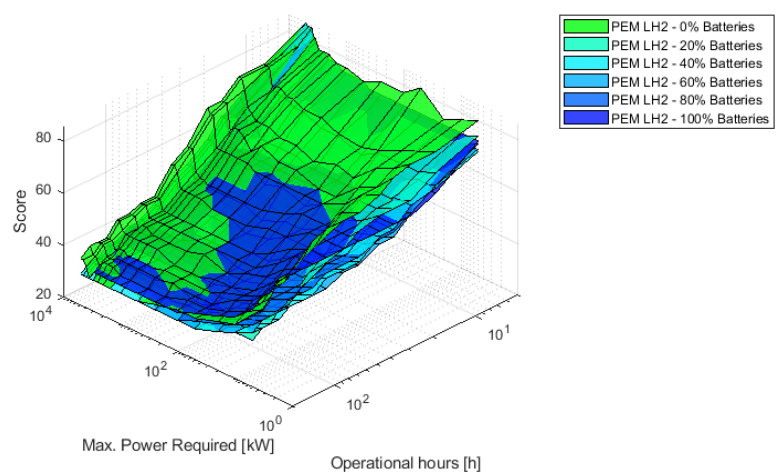

Fig. 10. 3D representation of the parametric dataset for PEMFC solutions paired with LH2 showing different score surfaces for different percentages of batteries, generated with a fixed relevance set of 4 for volume, 2 for weight and emissions, and 3 for cost.

\section{Conclusions}

This paper investigates the potentiality of the multicriteria decision method-based software HELM, which identifies the most suitable power system to be used in specific applications in the maritime field. Two applicative cases have been investigated.

In the first case study, a small passenger ship operating in urbas anreas, where the reduction of emissions has a high relevance, was considered. The simulation suggested the use of hydrogen fueled PEMFC as an excellent alternative to traditional FO engines. To investigate a different condition, the second case study is a large sized ship, where ICE is identified as the best technology due to the more stringent limits on volume and cost. However, a very good alternative to FO is a different fuel as LNG, which allows for a reduction in $\mathrm{CO} 2$, NOx and SOx emissions.

Finally, the use of batteries was investigated for small size ships: from the analysis, batteries result suitable in a small range of sizes and operational hours, anyway they are included in the options available in HELM.

The study cases analyzed are only two of all those considered during research activities conducted by the authors' research group. The decisional criterion has been tested on many cases, always returning results that are likely, proving the reliability of the algorithm. Furthermore, by inserting technologies with reduced environmental impact in the HELM database, the software shows unconventional options suitable for particular applications, in order to move towards decarbonization in the maritime field and a more sustainable future.

The Authors wish to thank Lorenzo Clerici and Stefano Bottino, graduated students at University of Genoa, for their contribution to this research activity.

\section{References}

1. https://www.iea.org/statistics/ International Energy Agency (IEA) official website, last access 8/9/2021.

2. Maritime forecast to 2050-Energy transition outlook (2021), DNV Maritime.

3. MARPOL Annex VI - Prevention of Air Pollution from Ships (2020), International Maritime Organization (IMO).

4. https://www.imo.org/en/MediaCentre/HotTopics/Pag es/Reducing-greenhouse-gas-emissions-from-

ships.aspx International Maritime Organization (IMO) official website, last access 8/9/2021.

5. T. Ouyang, J. Tan, S. Xie, W. Wu, Z. Su, Energy Conversion and Management, 229 (2021), 113770.

6. J.E. Fokkema, P. Buijs, I.F.A. Vis, Transportation Research, Transport Environ., 56 (2017), 229-240.

7. P. Balcombe et al, En. Conv. and Manag., 182 (2019), 72-88.

8. M. Prussi, N. Scarlat, M. Acciaro, V. Kosmas, J. of Cleaner Production, 291 (2021), 125849.

9. N.R. Ammar, Transportation Research, Transport Environ., 69 (2019), 66-76.

10. L. van Biert, M.Godjevac, K.Visser, P.V.Aravind, Journal of Power Sources, 327 (2016), 345-364.

11. Rivarolo M, Rattazzi D, Magistri L, Int. J. of Hydrogen En., 43 (2018), 23500-23510.

12. H. Sapra, J. Stam, J. Reurings, L. van Biert, W. van Sluijs et al., App. En., 281 (2021), 115854.

13. Gadducci E, Thomas L, Bellotti D, Magistri M, Massardo AF, Int J. of Hydrogen En., 46 (2021), 24305-24317.

14. O.B. Inal, C. Deniz, Journal of Cleaner Production, 265 (2020), 121734.

15. A. Bouakkaz, A.J.G. Mena, S. Haddad, M.L. Ferrari, 2021, J. of En. Storage, 33 (2021), 1-13.

16. A.F. Massardo, L. Magistri, J. of Eng. For Gas Turbine and Power, 125 (2003), 67-74.

17. R. Chauvy, R. Lepore, P. Fortemps, G. De Weireld, Sustainable Prod. and Cons., 24 (2020), 194-210.

18. A. Priftis, E. Boulougouris, O. Turan, A. Papanikolau, Ocean Eng., 156 (2018), 347-357.

19. M. Pesce, S. Terzi, R.I.M. Al-Jawasreh, C. Bommarito, L. Calgaro, et al., Science of the Total Environment, 642 (2018), 668-678.

20. http://www.tpg.unige.it/TPG/portfolio-item/helm/ last access 31/7/2021.

21. M. Rivarolo, D. Rattazzi, L. Magistri, A.F. Massardo, En. Conv. And Management, 244 (2021), 114506.

22. M. Rivarolo, D. Rattazzi, L. Magistri, Int. J. of Hydrogen En., 45 (2020), 25747-25757. 
23. www.vesselfinder.com last access 31/7/2021.

24. S. Jafarzadeh, I. Schjølberg, Transp. Research Part D: Transport and Env., 65 (2018), 500-523.

25. O'Hayre et al, Fuel Cell Fundamentals, 2016. 